\title{
The prognostic impact of epidermal growth factor receptor in patients with metastatic gastric cancer
}

\author{
Akin Atmaca ${ }^{*}$, Dominique Werner ${ }^{1}$, Claudia Pauligk¹, Kristina Steinmetz ${ }^{1}$, Ralph Wirtz², \\ Hans-Michael Altmannsberger ${ }^{3}$, Elke Jäger ${ }^{1}$ and Salah-Eddin Al-Batran ${ }^{1}$
}

\begin{abstract}
Background: The epidermal growth factor receptor (EGFR) is a potential target of anticancer therapy in gastric cancer. However, its prognostic role in metastatic gastric or gastroesophageal junction (GE) cancer has not been established yet.

Methods: EGFR status was analyzed by immunohistochemistry (IHC) in paraffin-embedded samples from 357 patients who received chemotherapy in 4 first-line trials. Automated RNA extraction from paraffin and RT-quantitative PCR were additionally used to evaluate EGFR mRNA expression in 130 patients.

Results: EGFR protein expression (any grade) and overexpression (3+) were observed in $43 \%$ and $11 \%$ of patients, respectively. EGFR positivity correlated with intestinal type histology $(p=0.05)$, but not with other clinicopathologic characteristics. Median follow-up was 18.2 months. Median overall survival (OS) was similar in patients with EGFR positive vs. those with EGFR negative tumors, regardless whether positivity was defined as $\geq 1+(10.6$ vs. 10.9 months, $p=0.463$ ) or as $3+$ (8.6 vs. 10.8 months, $p=0.377$ ). The multivariate analysis indicated that EGFR status is not an independent prognostic factor (hazard ratio $0.85,0.56$ to $1.12, p=0.247$ ). There were also no significant differences in overall survival when patients were categorized according to median $(p=0.116)$ or quartile $(p=0.767)$ distribution of EGFR mRNA gene expression. Similar distributions of progression-free survival according to EGFR status were observed.
\end{abstract}

Conclusions: Unlike different cancer types where EGFR-positive disease is associated with an adverse prognostic value, EGFR positivity is not prognostic of patient outcome in metastatic gastric or GE cancer.

Keywords: EGFR, Immunohistochemistry, Gastric cancer, Survival, Prognostic

\section{Background}

Despite reasonable improvement in the therapeutic management of advanced gastric cancer with new active regimens [1-3], the prognosis is still very limited, with a median overall survival of approximately 9 to 11 months. With the emergence of new therapeutic options, great effort is made in the research of biomarkers, which can help to identify subgroups of patients,

\footnotetext{
* Correspondence: atmaca.akin@khnw.de

'Department of Hematology and Oncology, Institute of clinical research (IKF) at Krankenhaus Nordwest, UCT-University Cancer Center, Frankfurt am Main, Germany

Full list of author information is available at the end of the article
}

who may benefit from special treatments. To date, human epidermal growth factor receptor 2 (HER2) overexpression (observed in up to $22 \%$ of patients) is the only predictive factor, which predicts a benefit from a treatment with the anti-HER2 antibody trastuzumab [4].

Aberrant epidermal growth factor receptor (EGFR) signaling plays an important role in development and progression of various human tumors. EGFR has been demonstrated to phosphorylate and regulate numerous cellular proteins and to initiate several signal transduction cascades, which lead to cell proliferation, migration, invasion, metastasis, angiogenesis and inhibition of apoptosis. While EGFR inhibitors for metastatic gastric

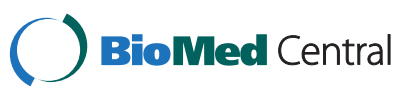


cancer are currently under investigation, the prognostic role of EGFR in gastric cancer remains controversial.

While many initial reports indicated unfavorable outcome for EGFR protein expression or overexpression in patients with resectable gastric cancer [5-11] some recent reports could not observe a correlation between EGFR expression and survival [12], or even found a significant correlation of high EGFR expression with favorable outcome in patients with curatively resected gastric cancer [13].

Regarding these particular controversial findings, which are partly based on different patient populations and different analysis methods, there is a need for clarifying the role of EGFR expression in a distinct setting and well defined patient population.

To clarify the clinical relevance of EGFR status, this study examines the clinicopathologic characteristics and outcomes in a uniform population of Western patients with gastric/GE junction adenocarcinoma enrolled in first-line metastatic chemotherapy trials.

\section{Methods \\ Patients}

Stage IV gastric cancer patients with available tissue for EGFR testing were indentified from a prospective database of four first-line trials of chemotherapy [14-17].

Patients gave written informed consent on participation in the clinical trial and on sample collection and analysis, which was approved by the responsible ethic committee (ethics committee of the Landesärztekammer Hessen, Germany). Standards of the International Conference on Harmonization/ World Health Organization (WHO) Good Clinical Practice were followed.

\section{Pathology review}

Formalin-fixed paraffin-embedded (FFPE) tumor samples were evaluated for EGFR protein expression by immunohistochemistry (IHC). For each case, a corresponding hematoxylin-eosin (H\&E) section was reviewed to assess the sample adequacy. All tumors were re-examined by a gastrointestinal pathologist (HA) to confirm the histological subtype (diffuse vs. intestinal vs. mixed).

\section{Immunohistochemistry}

Tissue sections ( $5 \mu \mathrm{m}$ thickness) were stained with H\&E or immunostained by indirect immunoperoxidase method (DAKO, Glostrup, Denmark) as recommended by the manufacturer. For detection of EGFR the EGFR pharmDx TM Kit for the Dako Autostainer was used. Tissue staining was visualized with a DAB substrate chromogen solution. Slides were counterstained with hematoxilin, dehydrated and mounted.

Membrane staining was evaluated in the neoplastic cells and quantified and graded as recommended in the detection kit (primary scoring system): 0 , no staining or membranous reactivity in $<10 \%$ of tumor cells; $1+$, weak, barely perceptible membranous reactivity in $>10 \%$ of tumor cells; $2+$, complete or basolateral membranous reactivity either non-uniform or weak in at least $10 \%$ of cells; $3+$, complete or basolateral membranous reactivity of strong intensity in $\geq 10 \%$ of cells. Additionally the following two scoring systems were also evaluated:

1.) H-Score: The score was obtained by the formula: $3 \mathrm{x}$ percentage of strongly staining nuclei $+2 \mathrm{x}$ percentage of moderately staining nuclei + percentage of weakly staining nuclei, giving a range of 0 to 300 . Samples with score $>200$ were classified as positive (overexpression) [18].

2.) Modified semiquantitative $\mathrm{H}$-score: intensity of staining from 0 to 3 multiplied by the percentage of positive tumor cells, which were categorized as 0.1 for $1-9 \%, 0.5$ for $10-49 \%$ and 1.0 for $>50 \%$ positive tumor cells. A score $>1.0$ was classified as positive [19].

\section{RNA extraction and gene expression analysis}

Formalin-fixed paraffin-embedded (FFPE) tumor samples were evaluated for mRNA expression. From each tumor block, a $5-\mu \mathrm{m}$ section was stained with hematoxylin-eosin and revised by a pathologist and two consecutive $10-\mu \mathrm{m}$ sections were cut on a standard microtome, tumor was macro-dissected and placed into individual tubes, and stored at $4^{\circ} \mathrm{C}$ for $\sim 1$ month until RNA extraction. Fully automated high-throughput RNA extraction has been carried out according to methods previously published [20].

Expression of EGFR and the normalization (housekeeping) gene RPL37A was assessed by one-step RTquantitative PCR (qPCR). SuperScript ${ }^{{ }^{\circledR}}$ III Platinum ${ }^{\circledR}$ One-Step qRT-PCR System with ROX (Invitrogen, Karlsruhe, Germany) was used according to the manufacturer's instructions. Experiments were carried out on an ABI PRISM ${ }^{\circledR} 7900 \mathrm{HT}$ (Applied Biosystems, Darmstadt, Germany) with $30 \mathrm{~min}$ at $50^{\circ} \mathrm{C}, 2 \mathrm{~min}$ at $95^{\circ} \mathrm{C}$ followed by 40 cycles of $15 \mathrm{~s}$ at $95^{\circ} \mathrm{C}$ and $30 \mathrm{~s}$ at $60^{\circ} \mathrm{C}$. Relative copy numbers positively correlating with the expression of the genes of interest were calculated by using the 2(40-DDCT)-method. Each mRNA expression was adjusted with the housekeeping gene. For assessment of DNA contamination in RNA preparations, a PAEP gene-specific $\mathrm{qPCR}$ without preceding reverse transcription was carried out using the reagents from the SuperScript III ${ }^{\circledR}$ Platinum ${ }^{\circledR}$ One-Step qRTPCR System with ROX and Taq DNA Polymerase. In samples with a Cq value $<35$, the DNase I treatments were repeated to prevent effects on bispecific PCR assays. Stratagene human QPCR Reference total RNA (Stratagene, Waldbronn, Germany) was used as positive control for RTqPCR and human genomic DNA (Roche 
Diagnostics, Basel, Switzerland) as positive control for qPCR. All PCR assays were carried out in triplicate, and the mean of triplicates was reported. Kinetic RT-PCR was applied for the assessment of mRNA expression using the following TaqMan ${ }^{\mathrm{TM}}$-based primer/ probe set ${ }^{\mathrm{TM}}$-based primer/probe set (Eurogentec, Seraing, Belgium):

EGFR probe CCTTGCCGCAAAGTGTGTAACGGAAT. Forward primer CGCAAGTGTAAGAAGTGCGAA.

Reverse primer CGTAGCATTTATGGAGAGTGAGTCT.

\section{Statistical analysis}

Progression-free survival (PFS) and overall survival (OS) were calculated by the Kaplan-Meier method, and statistical significance was analyzed using the log-rank test. To assess the univariate relationship between clinicopathologic variables and EGFR-status (positive or negative), the Fishers' exact test was applied. Furthermore, Cox proportional hazard models were used for the multivariate analyses concerning survival times. All $p$ values were two-sided, with $p$ values $<0.05$ considered to indicate statistical significance.

\section{Results}

\section{Patient characteristics}

The cohort consists of 357 patients with stage IV adenocarcinoma of middle to distal stomach (65\%) or GE junction (30\%), with a similar number of Lauren's diffuse/mixed (48\%) and intestinal tumors (39\%). Liver was the most common site of metastatic disease (44\%). The majority of samples were from primary tumor (83\%) and were biopsy specimens (67\%). Patients predominantly presented with metastatic disease (83\%), and went on to receive three-drug combination chemotherapy (54\%). Table 1 summarizes patient characteristics.

The proportion of patients randomized in four different first-line trials with available tumor samples was $67.7 \%$ [14], 58.3\% [15], 28.7\% [16], and 52.4\% [17], respectively. There was no significant difference in patients' characteristics, regarding patients with available tumor samples and the entire study cohort.

One hundred ninety-two patients (54\%) received a three-drug regimen of oxaliplatin $85 \mathrm{mg} / \mathrm{m}^{2}$, leucovorin $200 \mathrm{mg} / \mathrm{m}^{2}$, and fluorouracil $2600 \mathrm{mg} / \mathrm{m}^{2}$ as a 24-hour infusion in combination with docetaxel $50 \mathrm{mg} / \mathrm{m}^{2}$ (FLOT) on day 1 every 2 weeks [15-17]. One hundred sixty-five patients (46\%) received a regimen of fluorouracil $2,600 \mathrm{mg} / \mathrm{m}^{2}$ via 24-hour infusion, leucovorin $200 \mathrm{mg} / \mathrm{m}^{2}$, and oxaliplatin $85 \mathrm{mg} / \mathrm{m}^{2}$ (FLO) every 2 weeks, or fluorouracil $2,000 \mathrm{mg} / \mathrm{m}^{2}$ via 24 -hour infusion, leucovorin $200 \mathrm{mg} / \mathrm{m}^{2}$ weekly, and cisplatin $50 \mathrm{mg} / \mathrm{m}^{2}$ every 2 weeks (FLP) [14].
Table 1 Patient Characteristics $(\mathrm{N}=357)$

\begin{tabular}{|c|c|}
\hline \multirow[t]{2}{*}{ Characteristic } & \multirow{2}{*}{$\frac{\text { Patients }}{\mathrm{N}(\%)}$} \\
\hline & \\
\hline \multicolumn{2}{|l|}{ Age, median (range) } \\
\hline \multicolumn{2}{|l|}{ Sex } \\
\hline Male & $214(60)$ \\
\hline Female & $143(40)$ \\
\hline ECOG performance status 0-1 & $326(91)$ \\
\hline \multicolumn{2}{|l|}{ Primary tumor location } \\
\hline Gastroesophageal junction/proximal stomach & $107(30)$ \\
\hline Mid to distal stomach & $231(65)$ \\
\hline Unclassifiable/Unknown & $19(5)$ \\
\hline \multicolumn{2}{|l|}{ Disease status } \\
\hline Stage IV at diagnosis & $298(83)$ \\
\hline z Recurrent disease & $59(17)$ \\
\hline \multicolumn{2}{|l|}{ First-line chemotherapy } \\
\hline 3-drug combination (FLOT) & $192(54)$ \\
\hline 2-drug combination (FLO or FLP) & $165(46)$ \\
\hline \multicolumn{2}{|l|}{ Metastatic disease sites } \\
\hline Liver & $157(44)$ \\
\hline Lymph nodes & $219(61)$ \\
\hline Peritoneum & $93(26)$ \\
\hline Lung & $60(17)$ \\
\hline \multicolumn{2}{|l|}{ Lauren classification } \\
\hline Diffuse/mixed & $170(48)$ \\
\hline Intestinal & $139(39)$ \\
\hline Other/Unknown & $48(13)$ \\
\hline \multicolumn{2}{|l|}{ Sampling specimen } \\
\hline Biopsy & $238(67)$ \\
\hline Surgical specimen & $116(33)$ \\
\hline Unknown & $3(1)$ \\
\hline Primary tumor & $298(83)$ \\
\hline Metastatic lesion & $50(14)$ \\
\hline Unknown & $9(3)$ \\
\hline
\end{tabular}

Abbreviations: FLOT, 5-FU, leucovorin, oxaliplatin and docetaxel; FLO, 5-FU, leucovorin, oxaliplatin; FLP, 5-FU, folic acid, cisplatin.

5-FU, Leucovorin and Oxaliplatin (FLO), 5-FU, Folic acid and Cisplatin (FLP).

\section{EGFR protein expression and correlation to} clinicopathologic characteristics

On IHC and according to the primary scoring system, 152 of 357 (43\%) patients tested EGFR-positive. EGFR was negative, 1+, 2+, and 3+ in 205 (57\%), 50 (14\%), 62 (17\%), and $40(11 \%)$ patients, respectively. With the modified semiquantitative $\mathrm{H}$-score, 116 (33\%) patients were classified as EGFR positive (>score 1.0) and $30(8 \%)$ patients had an H-score of $>200$ (EGFR overexpression).

Table 2 summarizes EGFR positivity rate according to baseline characteristics. The rate of EGFR positivity (any grade) was similar between biopsies and surgical specimens ( $41 \%$ vs $47 \% p=0.538)$, primary tumor and 
metastasis ( $42 \%$ vs $52 \% p=0.418$ ), histological subtypes (Lauren's intestinal type $48 \%$ vs $37 \%$ in diffuse type, $p=0.211$ ), in the proximal region encompassing gastric cardia/GE junction location and in the gastric body and antrum (44\% vs. $43 \%, p=0.916)$ and finally according to metastatic site (e.g. liver metastasis or not, $46 \%$ vs. $40 \%$, $p=0.559$ ).

Similar associations with clinicopathologic criteria were obtained when EGFR overexpression (EGFR 3+ group) was considered as positive, with the exception of histological subtype. Intestinal type tumors showed

Table 2 EGFR Positivity by Study Subgroup

\begin{tabular}{|c|c|c|c|}
\hline \multirow[t]{3}{*}{ Characteristic, $n=357$} & \multirow{3}{*}{$\frac{\text { EGFR neg }}{\frac{\text { (score 0) }}{n(\%)}}$} & \multirow{3}{*}{$\frac{\text { EGFR pos }}{\frac{\text { (score } 1-3+)}{n(\%)}}$} & \multirow{3}{*}{$\begin{array}{l}P \\
\text { Value }\end{array}$} \\
\hline & & & \\
\hline & & & \\
\hline Female, 143 & $79(55)$ & $64(45)$ & \\
\hline Male, 214 & $126(59)$ & $88(41)$ & .69 \\
\hline \multicolumn{4}{|l|}{ Age, } \\
\hline$>65,173$ & $96(55)$ & $77(45)$ & \\
\hline$\leq 65,181$ & $107(59)$ & $74(41)$ & .698 \\
\hline \multicolumn{4}{|l|}{ ECOG performance status, } \\
\hline $0-1,326$ & $186(57)$ & $140(43)$ & \\
\hline 2,22 & $11(50)$ & $11(50)$ & .697 \\
\hline Not specified, 9 & $8(89)$ & $1(11)$ & \\
\hline \multicolumn{4}{|l|}{ Primary tumor location } \\
\hline Gastroesophageal junction, 107 & $60(56)$ & $47(44)$ & \\
\hline Mid to distal stomach, 231 & $132(57)$ & $99(43)$ & .916 \\
\hline Not specified, 19 & $13(68)$ & $6(32)$ & \\
\hline \multicolumn{4}{|l|}{ Disease status } \\
\hline Stage IV at diagnosis, 298 & $171(57)$ & $127(43)$ & \\
\hline Recurrent disease, 59 & $34(58)$ & $25(42)$ & 1 \\
\hline \multicolumn{4}{|l|}{ Metastatic disease sites } \\
\hline Liver, present, 157 & $85(54)$ & $72(46)$ & \\
\hline Liver, not present, 199 & $119(60)$ & $80(40)$ & .559 \\
\hline Lymph nodes, present 219 & $127(58)$ & $92(42)$ & \\
\hline Lymph nodes, not present, 98 & $51(52)$ & $47(48)$ & .585 \\
\hline Peritoneum, present ,93 & $57(61)$ & $36(39)$ & \\
\hline Peritoneum, not present, 263 & $147(56)$ & $116(44)$ & .58 \\
\hline \multicolumn{4}{|l|}{ Lauren classification, } \\
\hline Diffuse/mixed, 170 & $107(63)$ & $63(37)$ & .211 \\
\hline Intestinal, 139 & $72(52)$ & $67(48)$ & \\
\hline Not specified, 48 & $26(54)$ & $22(46)$ & \\
\hline \multicolumn{4}{|l|}{ Specimen used for EGFR testing } \\
\hline Biopsy, 238 & $141(59)$ & $97(41)$ & \\
\hline Surgical specimen,116 & $62(53)$ & $54(47)$ & .538 \\
\hline Not specified, 3 & $2(67)$ & $1(33)$ & \\
\hline Primary tumor, 298 & $173(58)$ & $125(42)$ & \\
\hline Metastatic lesion, 50 & $24(48)$ & $26(52)$ & .418 \\
\hline Not specified, 9 & $9(100)$ & 0 & \\
\hline
\end{tabular}

significantly higher rates of EGFR $3+$ expression compared with diffuse/mixed type histology (16\% vs. $8 \%$, $p=0.05)$.

\section{Correlation between EGFR protein expression and survival}

A total of 297 deaths (83\%) had occurred at the time of analysis, with median follow-up for surviving patients of 18.2 months (range 3.3 to 44.1). There was no difference in OS and PFS between patients with EGFR positive and negative tumors with median OS and PFS being 10.9 vs.10.6 months $(p=0.463)$ and 5.3 vs 5.7 months $(p=0.185)$, respectively (Figure 1$)$. There was either no statistical difference regarding OS and PFS between the different EGFR + subgroups (1+ to 3+; P for trend = 0.581).

Median OS and PFS showed also no statistical difference when the modified semiquantitative $\mathrm{H}$-score $(>1.0$ vs $\leq 1.0)$ was applied $(p=0.544$ and $p=0.325$, respectively; data not shown). For the group with high EGFRexpression classified by the quantiative $\mathrm{H}$ - score $(>200)$, OS and PFS also remained not statistically different from those found in the lower expression group ( $p=0.764$ and $p=0.272$, respectively; data not shown).

Similar distributions of OS according to EGFR status were also observed when the survival analysis was adjusted for the use of docetaxel (yes or no; $p=0.390$ ) and the type of platinum used (oxaliplatin or cisplatin; $p=0.337)$.

In the multivariate analysis, including EGFR status, age, sex, two- vs. three-drug chemotherapy, histologic subtype, and disease status, EGFR status was not an independent predictor of overall survival (HR 0.85; $p=0.247$; Table 3). In the multivariate analysis only three-drug chemotherapy was significantly associated with longer survival time.

\section{Correlation between EGFR mRNA gene expression and survival}

In addition to EGFR IHC, EGFR mRNA expression was analyzed by realtime PCR in 130 of the 357 patients. EGFR mRNA levels correlated with protein levels in the tumor tissue. The median mRNA expression in patients with no EGFR protein expression was 252 copies versus a median of 298 copies in EGFR positive patients. The trend was also clearly visible in the different intensity grades of EGFR IHC staining (EGFR 1+: median mRNA 288; EGFR 2+: median mRNA 264; EGFR 3+: median mRNA 410). In line with the IHC results for protein expression, EGFR mRNA expression levels showed no significant correlation to overall or progression free survival. This was observed when the median was chosen as threshold (Figure 2) or when patients were grouped according to their quartile expression of EGFR mRNA (data not shown). 

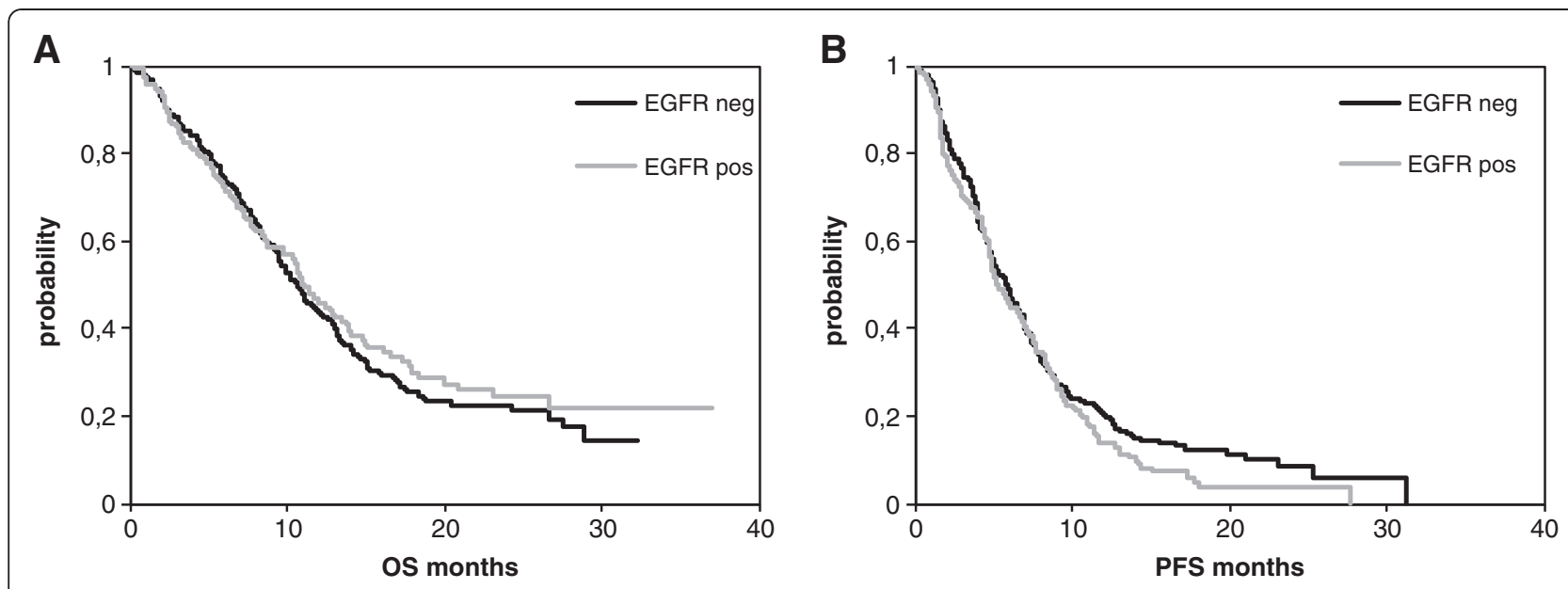

Figure 1 Kaplan-Meier curves for (A) overall survival (OS) and (B) progression free survival (PFS) for patients with EGFR-positive ( $n=152$ ) and EGFR-negative $(\boldsymbol{n}=\mathbf{2 0 5})$ disease. Median OS: 10.9 vs 10.6 months, $p=0.463$; median PFS: 5.3 vs 5.7 months, $p=0.185$.

\section{Discussion}

Our results show that EGFR status is not prognostic of patient outcome in metastatic gastric and GE junction adenocarcinoma. We also found no impact of EGFR status on progression-free survival, indicating that EGFR overexpression is not associated with more aggressive tumor biology or with resistance to chemotherapy in gastric and GE junction adenocarcinoma. Our analysis is based on a large and uniform cohort of Western patients with metastatic gastric cancer, all treated with standardized chemotherapy in a clinical trial. EGFR testing was performed according to different scoring systems and methods (protein and mRNA gene expression) reviewed by referenced pathologists, with other clinical and pathological characteristics captured prospectively in research databases. Unlike other studies, our cohort consists solely of patients with stage IV disease with well annotated chemotherapy data available on all of our patients, and none received EGFR targeted therapies in the firstor second-line setting. Our cohort is by far the largest $(n=357)$ reporting on the prognostic effect of EGFR on metastatic disease gastric cancer. Previous data from

Table 3 Univariate and multivariate overall survival analyses

\begin{tabular}{|c|c|c|}
\hline Characteristic & Hazard ratio $(95 \% \mathrm{Cl})$ & $\underline{P \text {-value }}$ \\
\hline EGFR positive vs EGFR negative & $0.91(0.66$ to 1.16$)$ & .464 \\
\hline Age $>65$ vs $\leq 65$ & 1.04 (0.80 to 1.29$)$ & .747 \\
\hline ECOG performance status 2-3 vs 0-1 & $2.13(1.66$ to 2.60$)$ & .002 \\
\hline Therapy with 2- drug vs 3- drug combination & $0.82(0.58$ to 1.07$)$ & .117 \\
\hline gastroesophageal junction vs Stomach & 0.69 (0.40 to 0.97$)$ & .009 \\
\hline recurrent disease vs Stage IV at diagnosis & 0.84 (0.50 to 1.18$)$ & .326 \\
\hline Male vs female & 0.92 (0.67 to 1.17$)$ & .512 \\
\hline Liver metastasis, yes vs no & 1.19 (0.95 to 1.44$)$ & .163 \\
\hline Peritoneal metastasis, yes vs no & 1.26 (1.00 to 1.52$)$ & .079 \\
\hline Intestinal vs diffuse/mixed & $0.90(0.63$ to 1.16$)$ & .43 \\
\hline \multicolumn{3}{|l|}{ Multivariate Overall Survival Analysis } \\
\hline$\underline{\text { Characteristic }}$ & Hazard ratio $(95 \% \mathrm{Cl})$ & $\underline{p \text {-value }}$ \\
\hline EGFR positive vs EGFR negative & 0.85 (0.57 to 1.13$)$ & .247 \\
\hline Age $>65$ vs $\leq 65$ & $1.16(0.88$ to 1.45$)$ & .299 \\
\hline Therapy with 2- drug vs 3- drug combination & 0.71 (0.39 to 0.97) & .033 \\
\hline gastroesophageal junction vs Stomach & $0.78(0.43$ to 1.14$)$ & .176 \\
\hline recurrent disease vs Stage IV at diagnosis & $0.71(0.33$ to 1.10$)$ & .087 \\
\hline Male vs female & $1.01(0.71$ to 1.30$)$ & .959 \\
\hline Intestinal vs. diffuse/mixed & 0.9 (0.59 to 1.22$)$ & .517 \\
\hline
\end{tabular}

${ }^{a}$ Univariate Overall Survival Analysis. 

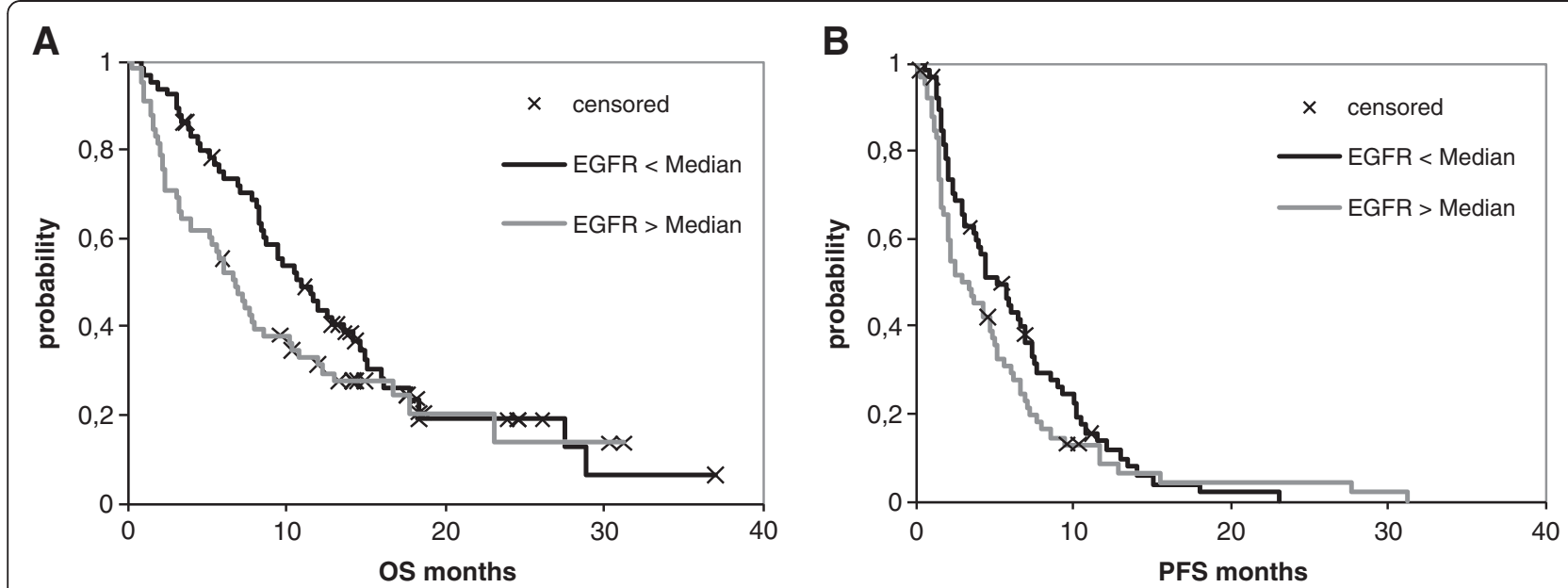

Figure 2 Kaplan-Meier curves for (A) overall survival (OS) and (B) progression free survival (PFS) for patients with EGFR-mRNA > median expression $(\boldsymbol{n}=\mathbf{6 5})$ and EGFR-mRNA < median expression $(\boldsymbol{n}=\mathbf{6 5})$. Median OS: 6.8 vs 10.7 months, $p=0.173$; median PFS: 2.9 vs 5.9 months, $p=0.116$

patients with metastatic gastric cancer are limited to two cohorts of 86 and 43 patients and have delivered conflicted results regarding the prognostic value $[10,21]$.

Regarding the curable stages, more data exist but the prognostic role of EGFR expression in operable gastric cancer remains controversial. Expression of EGFR in resected gastric cancer has been linked to shorter overall survival, more advanced tumor stage, and lymph node metastases in some studies, but not in others [5-9,12,13]. For example, Kim et al. [13] found a correlation of EGFR expression and improved overall survival in patients with resected gastric cancer receiving adjuvant chemotherapy.

The controversial findings in resectable stages may particularly derive from missing standardized procedures and the lack of an established scoring system in the immunohistochemical evaluation of EGFR. Besides proper definition of the target population and tumor characteristics, it is important to reflect distinct information of immunohistochemical EGFR expression like intensity of staining, staining pattern (focal or homogenous), content of tumor cells and choice of primary antibodies.

Although EGFR is not a prognostic factor in metastatic gastric cancer, this is not a reflection on its value as a predictive marker. This is in line with recent results from HER2, which is an established predictive factor for treatment response to trastuzumab, while (according to recent reports) Her2 expression itself is not a prognostic factor in metastatic gastric cancer [4,22,23].

While no associations between Her2 expression (any grade) and clinicopathologic criteria were seen, we found that the rate of EGFR 3+ status was significantly associated with intestinal type histology (intestinal, 16\%; diffuse, $8 \% ; p=0.05)$. The same pattern is known form Her2 expression [4,22] and may indicate a link between high expression of the erb-receptor family and a distinct disease biology in gastric cancer. In the TOGA-trial [4] it was shown that the extent of Her2 expression is of relevant predictive value. It was clearly demonstrated, that anti HER2 treatment is only reasonable in patients with high intensity HER2 expression (HER2 score 3+). Whether this observation will be applicable to EGFR inhibitors is unclear.

With emerging development of drugs interacting with the EGF receptor or the EGFR pathway with monoclonal antibodies like cetuximab and panitumumab, there is an enormous need of better understanding the way of interaction of these drugs and the need of identifying subgroups of patients, who are likely to have a clinical benefit.

In the clinical setting, anti EGFR antibodies seem to enhance the activity of chemotherapy with improved response rates up to $60 \%$ [24]. But recently presented results of a phase III study (REAL-3, [25]) comparing a first-line palliative chemotherapy (epirubicin, oxaliplatin and capecitabin) with or without the anti-EGFR antibody panitumumab, could not demonstrate an OS/PFS benefit or even showed a worse outcome in patients in the experimental arm.

It will be interesting if these studies could identify molecular subgroups of patients, who nevertheless could benefit from an EGFR targeted treatment.

\section{Conclusion}

Unlike different cancer types where EGFR-positive disease is associated with an adverse prognostic value, EGFR positivity is not prognostic of patient outcome in metastatic gastric or GE cancer.

\section{Competing interest}

The authors declare that there are no conflicts of interest. 


\section{Authors' contribution}

AA carried out the analysis of the immunohistochemistry and drafted the manuscript, DW carried out the immunohistochemistry and the statistical analysis, CP participated in the design of the study and performed the statistical analysis, KS carried out the immunohistochemistry, RW carried out the mRNA analysis, HA carried out the analysis of the immunohistochemistry, JE participated in the design and coordination of the study, SA designed and coordinated the study, carried out the immunhistochemistry and helped to draft the manuscript. All authors read and approved the final manuscript.

\section{Author details}

'Department of Hematology and Oncology, Institute of clinical research (IKF) at Krankenhaus Nordwest, UCT-University Cancer Center, Frankfurt am Main, Germany. ${ }^{2}$ STRATIFYER Molecular Pathology GmbH, Köln, Germany. Institute for Pathology, Krankenhaus Nordwest, Frankfurt am Main, Germany.

Received: 18 June 2012 Accepted: 10 November 2012 Published: 15 November 2012

\section{References}

1. Van Cutsem E, Moiseyenko VM, Tjulandin S, Majlis A, Constenla M, Boni C, Rodrigues A, Fodor M, Chao Y, Voznyi E, Risse ML, Ajani JA, V325 Study group: Phase III study of docetaxel and cisplatin plus fluorouracil compared with cisplatin and fluorouracil as first-line therapy for advanced gastric cancer: a report of the V325 study group. J Clin Oncol 2006, 24:4991-4997.

2. Al-Batran SE, Hartmann JT, Hofheinz R, Homann N, Rethwisch V, Probst S, Stoehlmacher J, Clemens MR, Mahllberg R, Fritz M, Seipelt G, Sievert M, Pauligk C, Atmaca A, Jäger E: Biweekly fluorouracil, leucovorin, Oxaliplatin, and docetaxel (FLOT) for patients with metastatic adenocarcinoma of the stomach or esophagogastric junction: a phase II trial of the Arbeitsgemeinschaft Internistische Onkologie. Ann Onc 2008, 19:1882-1887.

3. Cunningham D, Starling N, Rao S, Iveson T, Nicolson M, Coxon F, Middleton G, Daniel F, Oates J, Norman AR: Capecitabine and Oxaliplatin for advanced esophagogastric cancer. N Engl I Med 2008, 358:36-46.

4. Bang Y, Van Cutsem E, Feyereislova A, Chung HC, Shen L, Sawaki A, Lordick F, Ohtsu A, Omuro Y, Satoh T, Aprile G, Kulikov E, Hill J, Lehle M, Rüschoff J, Kang YK: Trastuzumab in combination with chemotherapy versus chemotherapy alone for treatment of HER2-positive advanced gastric or gastro-Oesophageal junction cancer (ToGA): a phase 3, open-label, randomised controlled trial. Lancet 2010, 376:687-697.

5. García I, Vizoso F, Martín A, Sanz L, Abdel-Lah O, Raigoso P, García-Muñiz JL: Clinical significance of the epidermal growth factor receptor and HER2 receptor in resectable gastric cancer. Ann Surg Oncol 2003, 10:234-241.

6. Galizia G, Lieto E, Orditura M, Castellano P, Mura AL, Imperatore V, Pinto M, Zamboli A, De Vita F, Ferraraccio F: Epidermal growth factor receptor (EGFR) expression is associated with a worse prognosis in gastric cancer patients undergoing curative surgery. World J Surg 2007, 31:1458-1468.

7. Gamboa-Dominguez A, Dominguez-Fonseca C, Quintanilla-Martinez L, Reyes-Gutierrez E, Green D, Angeles-Angeles A, Busch R, Hermannstädter C, Nährig J, Becker KF, Becker I, Höfler H, Fend F, Luber B: Epidermal growth factor receptor expression correlates with poor survival in gastric adenocarcinoma from Mexican patients: a multivariate analysis using a standardized immunohistochemical detection system. Mod Pathol 2004, 17:579-587.

8. Lieto E, Ferraraccio F, Orditura M, Castellano P, Mura AL, Pinto M, Zamboli A, De Vita F, Galizia G: Expression of vascular endothelial growth factor (VEGF) and epidermal growth factor receptor (EGFR) is an independent prognostic indicator of worse outcome in gastric cancer patients. Ann Surg Oncol 2008, 15:69-79.

9. Kim MA, Lee HS, Lee HE, Jeon YK, Yang HK, Kim WH: EGFR in gastric carcinomas: prognostic significance of protein overexpression and high gene copy number. Histopathology 2008, 52:738-746.

10. Matsubara J, Yamada Y, Nakajima TE, Matsubara J, Yamada Y, Nakajima TE, Kato K, Hamaguchi T, Shirao K, Shimada Y, Shimoda T: Clinical significance of insulin-like growth factor type 1 receptor and epidermal growth factor receptor in patients with advanced gastric cancer. Oncology 2008, 74:76-83.

11. Terashima M, Ochiai A, Kitada K, Ichikawa W, Kurahashi I, Sakuramoto S, Fukagawa T, Sano T, Imamura H, Sasako M: Impact of human epidermal growth factor receptor (EGFR) and ERBB2 (HER2) expressions on survival in patients with stage II/III gastric cancer, enrolled in the ACTS-GC study [abstract]. J Clin Oncol 2011, 29(4013):259.

12. Song HS, Do YR, Kim IH, Sohn SS, Kwon KY: Prognostic significance of immunohistochemical expression of EGFR and C-erbB-2 oncoprotein in curatively resected gastric cancer. Cancer Res Treat 2004, 36:240-245.

13. Kim JS, Kim MA, Kim TM, Lee SH, Kim DW, Im SA, Kim TY, Kim WH, Yang HK, Heo DS, Bang YJ, Lee KU, Choe KJ, Kim NK: Biomarker analysis in stage IIIIV (M0) gastric cancer patients who received curative surgery followed by adjuvant 5 -fluorouracil and cisplatin chemotherapy: epidermal growth factor receptor (EGFR) associated with favourable survival. $\mathrm{Br} J$ Cancer 2009, 10:732-738

14. Al-Batran SE, Hartmann JT, Probst S, Schmalenberg H, Hollerbach S, Hofheinz R, Rethwisch V, Seipelt G, Homann N, Wilhelm G, Schuch G, Stoehlmacher J, Derigs HG, Hegewisch-Becker S, Grossmann J, Pauligk C, Atmaca A, Bokemeyer C, Knuth A, Jäger E: Phase III trial in metastatic gastroesophageal adenocarcinoma with fluorouracil, leucovorin plus either Oxaliplatin or cisplatin: a study of the Arbeitsgemeinschaft Internistische Onkologie. J Clin Oncol 2008, 26(9):1435-1442.

15. Al-Batran SE, Hartmann JT, Hofheinz R, Homann N, Rethwisch V, Probst S, Stoehlmacher J, Clemens MR, Mahlberg R, Fritz M, Seipelt G, Sievert M, Pauligk C, Atmaca A, Jäger E: Biweekly fluorouracil, leucovorin, oxaliplatin, and docetaxel (FLOT) for patients with metastatic adenocarcinoma of the stomach or esophagogastric junction: a phase II trial of the Arbeitsgemeinschaft Internistische Onkologie. Ann Oncol 2008, 19:1882-1887.

16. Al-Batran S, Homann N, Hartmann JT, et al: 5-Fluorouracil, leucovorin, and Oxaliplatin with or without docetaxel in elderly (65 years or older) patients with esophagogastric cancer: FLOT65+ trial of the Arbeitsgemeinschaft Internistische Onkologie (AIO). J Clin Oncol 2010, 28(suppl):15s. Abstr 4013.

17. Al-Batran S, Hofheinz R, Homann N, et al: Defining two prognostic groups of metastatic gastric cancer: FLOT3 trial of the Arbeitsgemeinschaft Internistische Onkologie (AIO). J Clin Oncol 2011, 29(Suppl):273. Abstr 4070

18. Ishibashi H, Suzuki T, Suzuki S, Moriya T, Kaneko C, Takizawa T, Sunamori M Handa M, Kondo T, Sasano H: Sex steroid hormone receptors in human thymoma. J Clin Endocrinol Metab 2003, 88:2309-2317.

19. Olaussen KA, Dunant A, Fouret P, Brambilla E, André F, Haddad V, Taranchon E, Filipits M, Pirker R, Popper HH, Stahel R, Sabatier L, Pignon JP, Tursz T, Le Chevalier T, Soria JC, IALT Bio investigators: DNA repair by ERCC1 in non-small-cell lung cancer and cisplatin-based adjuvant chemotherapy. N Engl J Med 2006, 355:983-991.

20. Bohmann K, Hennig G, Rogel U, Poremba C, Mueller BM, Fritz P, Stoerkel S, Schaefer KL: RNA extraction from archival formalin-fixed paraffinembedded tissue: a comparison of manual, semiautomated, and fully automated purification methods. Clin Chem 2009, 55:1719-1727.

21. Matsubara J, Nishina T, Yamada Y, Moriwaki T, Shimoda T, Kajiwara T, Nakajima TE, Kato K, Hamaguchi T, Shimada Y, Okayama Y, Oka T, Shirao K: Impacts of excision repair cross-complementing gene 1 (ERCC1), dihydropyrimidine dehydrogenase, and epidermal growth factor receptor on the outcomes of patients with advanced gastric cancer. $\mathrm{Br} J$ Cancer 2008, 26:832-839

22. Janjigian YY, Werner D, Pauligk C, Steinmetz K, Kelsen DP, Jäger E, Altmannsberger HM, Robinson E, Tafe L, Tang LH, Shah MA, Al-Batran SE: Prognosis of metastatic gastric cancer by HER2 status: a European and US international collaborative analysis. Ann Oncol 2012, [in press].

23. Linos K, Sheehan CE, Ross JS: Correlation of HER2 and PTEN status with clinical outcome in esophageal (E), gastric (G), and gastroesophageal junction (GE) adenocarcinomas (ACs). J Clin Oncol 2011, 29(suppl):15s. Abstr 4066

24. Okines A, Cunningham D, Chau I: Targeting the human EGFR family in esophagogastric cancer. Nat Rev Clin Onco 2011, 8:492-503.

25. Waddell TS, Chau I, Barbachano Y, Gonzalez De Castro D, Wotherspoon A, Saffery C, Middleton GW, Wadsley J, Ferry DR, Mansoor W, Crosby TD, Coxon FY, Smith D, Waters JS, Iveson T, Falk S, Slater S, Okines AF, Cunningham D: A randomized multicenter trial of Epirubicin, Oxaliplatin, and capecitabine (EOC) plus panitumumab in advanced esophagogastric cancer (REAL3) [abstract]. J Clin Oncol 2012, 30(LBA4000):239.

doi:10.1186/1471-2407-12-524

Cite this article as: Atmaca et al.: The prognostic impact of epidermal growth factor receptor in patients with metastatic gastric cancer. BMC Cancer 2012 12:524 